HINKS: THE PERSISTENCE OF HYDROGEN PEROXIDE IN MILK

\title{
THE PERSISTENCE OF HYDROGEN PEROXIDE IN MILK.
}

By E. HINKS, F.I.C.

(Read at the Meeting, November 3, 1915.)

Considerable attention has, during recent years, been given to the determination of the catalytic activity of milk, and to the question of the usefulness of such determination for the purposes of milk control. Various methods have been proposed, and are in use, for effecting this determination.

Faitelowitz (ANALYst, 1910, 35, 526) shows that while the catalase of milk destroys hydrogen peroxide, the peroxide at the same time destroys the catalase, and consequently the rate of destruction of peroxide is not necessarily a measure of the amount of catalase. If the concentration of the peroxide is high, the destruction of catalase has a considerable influence upon the rate of destruction of peroxide, and a measure of the amount of catalase present can be obtained only by continued additions of small quantities of peroxide and observing the rate of destruction of the peroxide under these conditions. In this communication, when a figure for catalytic activity is given, this has been determined by Koning's iodimetric method as used by Revis (ANaLYst, 1910, 35, 359), and is numerically the number of c.c. of $\frac{\mathrm{N}}{10}$ Thiosulphate corresponding to the peroxide destroyed by the catalytic activity of 100 c.c. of the milk in two hours at $37^{\circ} \mathrm{C}$. In this method the concentration of the peroxide used is high.

The following experiments, in which the persistence of hydrogen peroxide has been studied, have a bearing both upon the determination of catalytic activity and upon the detection of peroxide in milk.

The length of time during which hydrogen peroxide at various concentrations persisted in different milks was first studied. Known quantities of peroxide were added to milk which was then allowed to stand at laboratory temperature, and the peroxide present at stated intervals was estimated iodimetrically, the procedure following that used in Koning's method for the catalytic activity determination (loc. cit.). Owing to occlusion of iodine by the casein the precise end-point of the titration is difficult to determine, and although the results of analysis are given to the third place of decimals this third place is hardly a significant figure.

It was found that the peroxide was destroyed rapidly at first, that the rate of destruction diminished, and that if the concentration of peroxide was high 
enough to withstand the first rapid destruction, the residual peroxide remained constant in amount over long periods.

The following example as typical of the results that were obtained may be given. In this case the peroxide concentration was high :

\section{Mirk I.}

Peroxide added, 0.5 per Cent.

\begin{tabular}{|c|c|c|c|c|c|c|c|}
\hline \multicolumn{3}{|c|}{ After 10 mins. } & \multirow{2}{*}{$\cdots$} & \multirow{2}{*}{$\cdots$} & \multirow{2}{*}{$\cdots$} & \multicolumn{2}{|c|}{$\begin{array}{l}\text { Peroxide Present. } \\
0.37 \text { per cent. }\end{array}$} \\
\hline ", & & ay & & & & 0.21 & $"$ \\
\hline$n$ & & lays & $\ldots$ & $\ldots$ & $\ldots$ & 0.20 & $"$ \\
\hline ", & 3 & $"$ & $\cdots$ & $\ldots$ & $\ldots$ & $0 \cdot 185$ & " \\
\hline , & 4 & ", & $\cdots$ & $\cdots$ & $\cdots$ & $0 \cdot 183$ & , \\
\hline$"$ & 5 & $"$ & $\cdots$ & $\cdots$ & $\cdots$ & 0.181 & " \\
\hline ", & 8 & ", & $\cdots$ & $\cdots$ & $\cdots$ & 0.182 & " \\
\hline ", & 14 & ", & $\ldots$ & $\ldots$ & $\ldots$ & $0 \cdot 182$ & $"$ \\
\hline
\end{tabular}

This milk (I.) was obtained in the usual way from a retailer. Another milk (XI.) was obtained immediately after being drawn, strained, and cooled. Peroxide was added to one portion (A); a second portion (B) was allowed to stand in the laboratory for twenty-four hours, when it received an addition of peroxide: peroxide (1.9 per cent.) was added to a third portion (C) after it had stood for three days. The amounts of residual peroxide were estimated at the intervals stated below. During the three days' standing the catalytic activity had risen from 32 for A to 158 for C.* After one hour no peroxide was present in C.

MrLK XI.

Catalytic Activity, 32 (Portion A).

A. B.

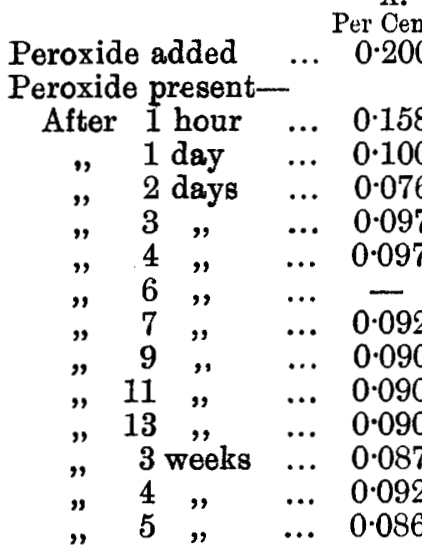

B.

\begin{tabular}{c|}
0.197 \\
0.146 \\
0.100 \\
0.110 \\
0.107 \\
$\overline{-}$ \\
0.103 \\
0.103 \\
$\overline{-}$ \\
0.101 \\
0.099 \\
0.098 \\
0.096
\end{tabular}

\section{Peroxide present-} After 6 weeks $\stackrel{\text { A. }}{\text { B. }}$ Per Cent.

* The results of the catalytic activity determinations were: Immediately after drawing, 32 ; after standing for one day, 24 ; after two days, 34; after three days, 158 . This was an isolated case, in which the catalytic activity appeared to diminish before the usual rise set in. That this was actually so in this case is not confirmed by the result after the lapse of one hour (the conditions were not the same as in the catalytic activity determination), but at subsequent times there was consistently more peroxide present in $B$ than in $A$, though $B$ received a slightly smaller addition of peroxide than did $A$. 


\section{HINKS : THE PERsistence OF HYDROGEN PEROXIDE IN MILK}

It will be seen that in this milk, though the initial concentration of peroxide was only 0.2 per cent., peroxide was still present in comparatively large amounts after a very considerable length of time in portions $A$ and $B$ : at the end of one year upwards of 33 per cent. of the peroxide added was still present.

The influence of the age and condition of milk upon the persistence of peroxide added to it is markedly shown in this experiment. The portions $\mathrm{A}$ and $\mathrm{C}$ had catalytic activities of 32 and 158 respectively. Neglecting the differences introduced by the different concentrations of peroxide used in the experiment and in the catalytic activity determination, and also the influence of temperature, calculation from the catalytic activity figures shows that $\mathrm{A}$ would reduce the peroxide concentration by 0.05 per cent. and $C$ would reduce it by 0.27 per cent. (absolute) in two hours. In $A$ and $B$ the peroxide concentration was high enough to stand this first rapid action by catalase : in $\mathrm{C}$ it was not. As a result, whilst the peroxide persisted in $\mathrm{A}$ and $\mathrm{B}$ for more than eighteen months, and was still present at the time of writing, in the case of $\mathrm{C}$ none remained after one hour, though $\mathrm{A}, \mathrm{B}$, and $\mathrm{C}$ were actually all portions of the same milk, and the initial concentrations of the peroxide were approximately equal.

Unqualified statements to the effect that any given quantity of peroxide will or will not persist for a given time, and can or cannot be detected after a given time, are, though frequently met with, valueless.* As is to be expected from the known

MILK VI.

Catalytic Activity, 39. Peroxide added, 0.195 per Cent.

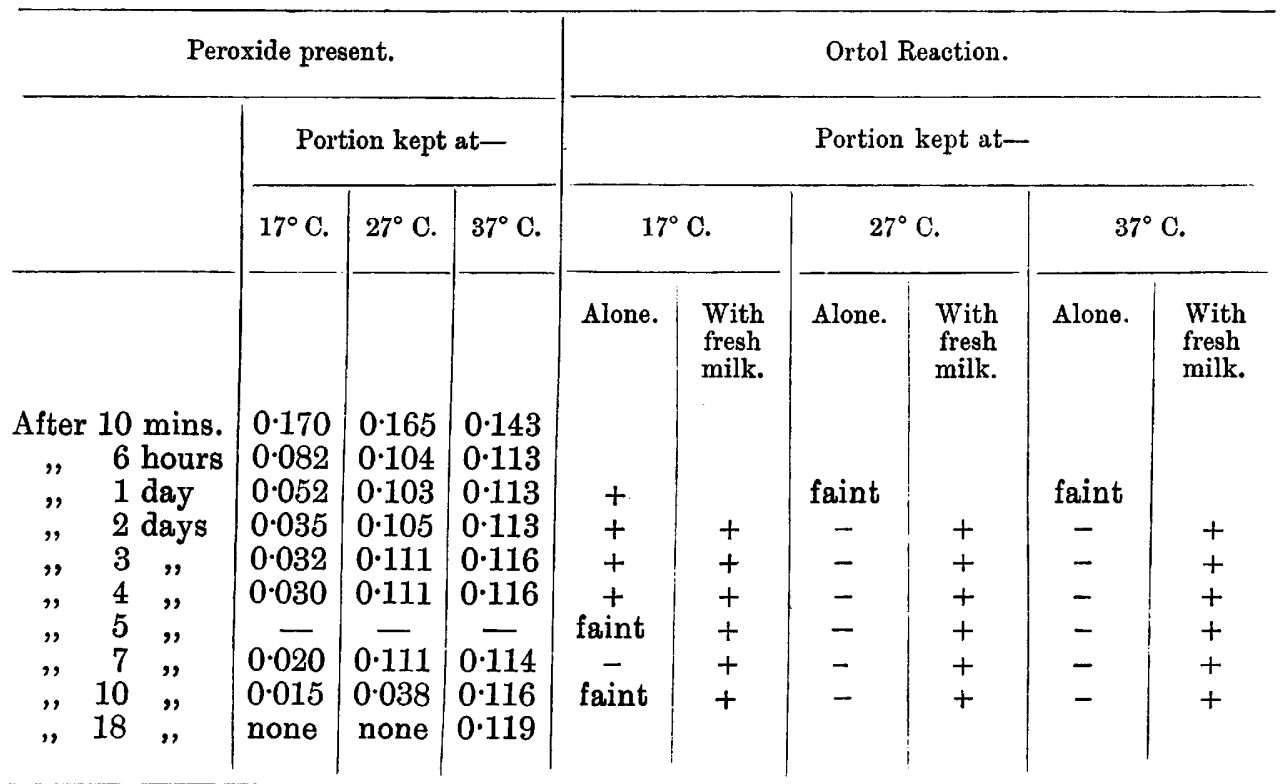

* From the results of those experiments that were performed with perfectly fresh milk, it would appear that it would be unusual if 0.1 per cent. of peroxide were to persist for twenty-four hours even if added to the milk immediately after being drawn, strained, and cooled. 
MiLK IV.

Catalytic Activity, 61. Peroxide added, 0.19 per Cent.

\begin{tabular}{|c|c|c|c|c|c|c|c|c|}
\hline & \multicolumn{8}{|c|}{ Portion kept at $15^{\circ} \mathrm{C}$. after- } \\
\hline & 10 Mins. & Hours. & 1 Day. & 3 Days. & 4 Days. & 6 Days. & 8 Days. & 11 Days. \\
\hline $\begin{array}{c}\text { Peroxide present } \\
\text { Reactions- } \\
\text { (a) Milk alone } \\
\text { (b) With peroxide }\left\{\begin{array}{l}\mathrm{O}^{*} \\
\mathrm{~B}^{*} \\
\mathrm{P}^{*}\end{array}\right. \\
\begin{array}{l}\mathrm{O} \\
\mathrm{B} \\
\mathrm{P}\end{array} \\
\text { (c) } \begin{array}{c}\text { With fresh } \\
\text { milk added } \\
\mathrm{B} \\
\mathrm{P}\end{array}\end{array}$ & $0 \cdot 148$ & 0.044 & $\begin{array}{l}0.024 \\
+ \\
\text { faint } \\
+ \\
\text { inc'd } \\
+ \\
+ \\
+ \\
+\end{array}$ & $\begin{array}{l}0.015 \\
+ \\
+ \\
\text { trace } \\
+ \\
+ \\
\text { trace } \\
+ \\
+ \\
+ \\
+\end{array}$ & $\begin{array}{l}0.008 \\
\\
+ \\
\text { trace } \\
+ \\
+ \\
\text { inc'd } \\
+ \\
+ \\
+ \\
+\end{array}$ & $\begin{array}{c}0.004 \\
- \\
- \\
- \\
\text { trace } \\
- \\
- \\
- \\
\text { trace } \\
-\end{array}$ & $\begin{array}{c}\text { none } \\
- \\
- \\
- \\
\text { trace } \\
- \\
- \\
- \\
-\end{array}$ & none \\
\hline
\end{tabular}

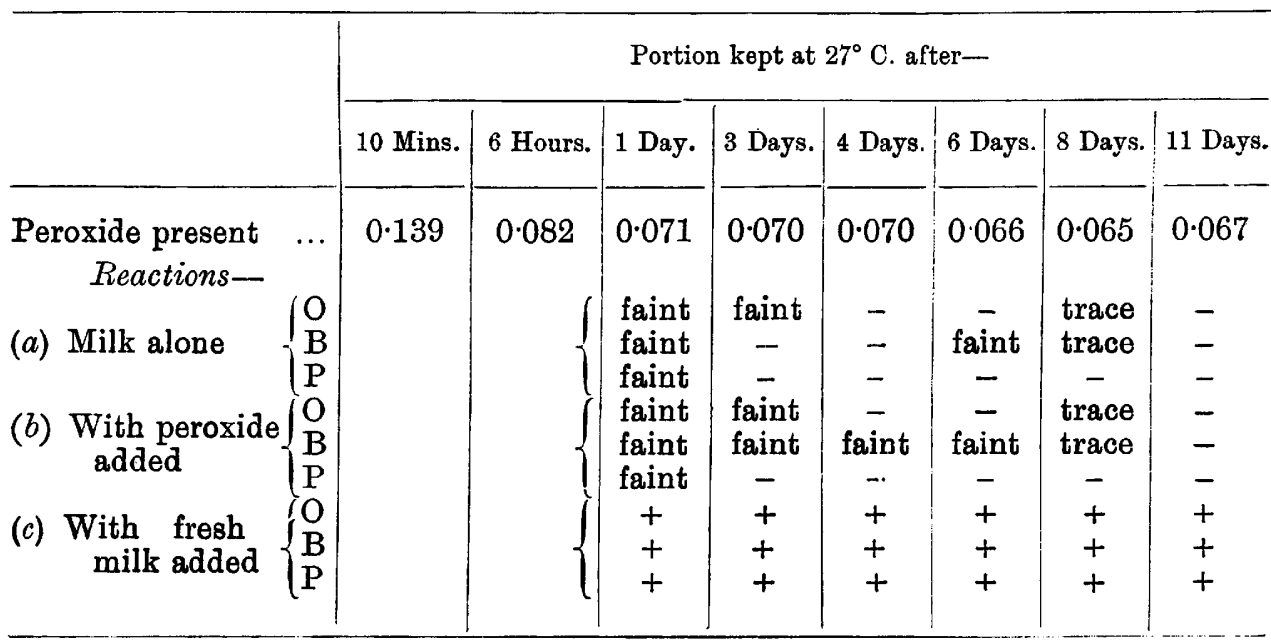

rise that takes place in the catalytic activity of milk on keeping, a most important factor in the behaviour of milk towards hydrogen peroxide is its age. It will be shown later, in connection with the peroxidase reactions, that if the milk has not been heated it is sometimes possible to infer that hydrogen peroxide has been added, though at the time of testing it is not present.

The influence of temperature was then studied. Peroxide was added in known quantities to milk, portions of which had been brought to, and were subsequently kept at, different temperatures. The results of several such experiments are given in the tables, the quantities of peroxide remaining in the various portions being estimated after the intervals stated.

* For an explanation of these letters see p. 487, under "The Peroxidase Reactions." 
Within the range of temperatures studied, the effect of a rise of temperature is to lengthen the time during which the peroxide persists. It is to be noted, however, that during the first few minutes the rate at which peroxide was destroyed was greater at the higher temperature. Thus in ten minutes in all cases more peroxide had been destroyed in the portions kept at the higher temperatures, but at the end of six hours this condition had been reversed.

It might be expected that, at any rate up to $37^{\circ} \mathrm{C}$., the higher the temperature the greater would be the catalytic activity, and the results obtained at the end of ten minutes indicate that this is so. The ultimate result, however, must be due to a resultant of destructive effects of the catalase on the peroxide and of the

MiLK III.

Catalytic Activity, 70. Peroxide added, 0.196 per Cent.

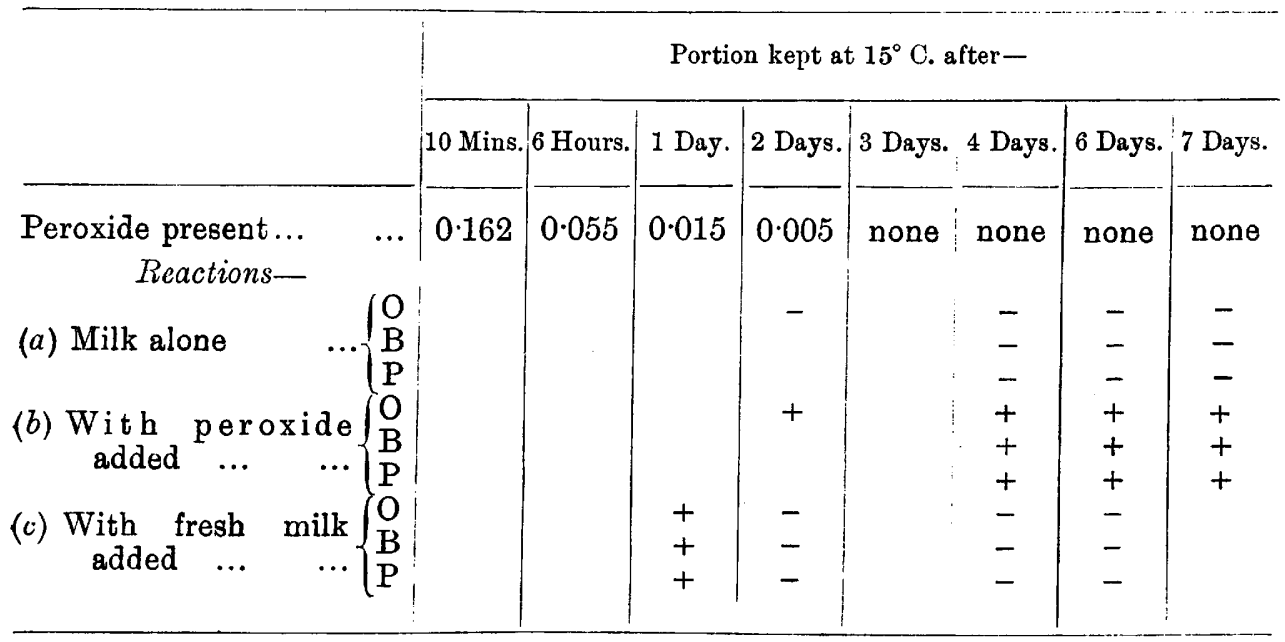

\begin{tabular}{|c|c|c|c|c|c|c|c|c|c|}
\hline & \multicolumn{9}{|c|}{ Portion kept at $27^{\circ} \mathrm{C}$. after- } \\
\hline & 10 Mins. & 6 Hours. & 1 Day. & 2 Days. & 3 Days. & 4 Days. & 6 Days. & 7 Days. & 9 Days. \\
\hline 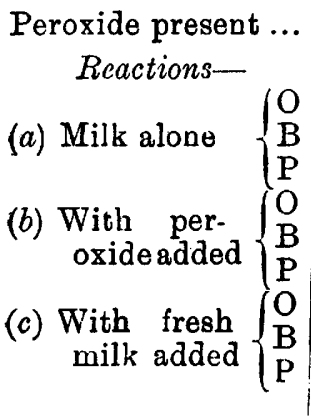 & $0 \cdot 150$ & 0.070 & 0.053 & $\begin{array}{l}0.046 \\
\text { trace } \\
\text { trace } \\
\\
+ \\
+ \\
+\end{array}$ & 0.050 & $\begin{array}{c}0.042 \\
- \\
- \\
- \\
- \\
- \\
- \\
+ \\
+ \\
+\end{array}$ & $\begin{array}{c}0.034 \\
- \\
- \\
- \\
- \\
\text { faint } \\
- \\
+ \\
+ \\
+\end{array}$ & $\begin{array}{c}0.008 \\
- \\
- \\
\overline{-} \\
\text { faint } \\
- \\
\overline{-} \\
-\end{array}$ & $\begin{array}{c}\text { none } \\
- \\
- \\
- \\
-\end{array}$ \\
\hline
\end{tabular}


MiLK V.

Catalytic Activity, 132. Peroxide added, 0.10 per Cent.

\begin{tabular}{|c|c|c|c|c|c|c|c|c|c|}
\hline & & \multicolumn{4}{|c|}{ Portion kept at $14^{\circ} \mathrm{C}$. after- } & \multicolumn{4}{|c|}{ Portion kept at $27^{\circ}$ C. after- } \\
\hline & & 10 Mins. & 6 Hours. & 1 Day. & 2 Days. & 10 Mins. & 6 Hours. & 1 Day. & 2 Days. \\
\hline $\begin{array}{l}\text { Peroxide present } \\
\text { Reactions- } \\
\text { (a) Milk alone } \\
\text { (b) With peroxide } \\
\text { added } \\
\text { (c) With fresh } \\
\text { milk added }\end{array}$ & \begin{tabular}{l|l}
$\cdots$ \\
\\
$B$ \\
$B$ \\
$P$ \\
$O$ \\
$B$ \\
$P$ \\
0 \\
$B$ \\
$P$
\end{tabular} & 0.076 & 0.003 & $\begin{array}{l}\text { none } \\
- \\
- \\
- \\
+ \\
+ \\
+ \\
- \\
- \\
-\end{array}$ & $\begin{array}{l}- \\
- \\
- \\
+ \\
+ \\
+ \\
- \\
- \\
-\end{array}$ & 0.065 & 0.006 & $\begin{array}{c}\text { none } \\
- \\
- \\
- \\
- \\
- \\
- \\
- \\
- \\
-\end{array}$ & $\begin{array}{l}- \\
- \\
- \\
- \\
- \\
-\end{array}$ \\
\hline
\end{tabular}

peroxide on the catalase. If the latter action is enhanced by a rise of temperature to an extent equal to or greater than the former, then there would be, at an elevated temperature, at first a more rapid destruction of peroxide, due to increased catalytic activity, followed by a less rapid destruction, due to disappearance of catalase. If this be the correct explanation of the results obtained, it would follow that in a method for the determination of the catalytic activity in which an excess of peroxide is employed for a period of some hours, an elevated temperature would be likely to result in a lower figure being obtained. The reverse would occur if the catalytic activity were high enough to reduce quickly the effective concentration of the peroxide.*

\section{The Peroxidase Reactions.}

Orthomethylaminophenol sulphate ("ortol"), benzidine, and paraphenylenediamine have been used for the detection of hydrogen peroxide in milk. They are also used for the detection of previous heating of milk. The reactions of these reagents with the milk to which peroxide had been added were accordingly observed during the course of these experiments, the reactions being noted as positive or negative against the letters $O, B$, and $P$ in the tables, these letters denoting the reagents in the order named above.

The reactions depend upon the simultaneous presence in the milk of hydrogen peroxide and a peroxidase. As in the case of catalase, hydrogen peroxide destroys peroxidase, and a negative reaction may consequently be due not to the absence of peroxide, but to the absence of peroxidase, which has been caused either by previous heating of the milk or by the peroxide which is being tested for. The reactions were

* In a few cases the catalytic activity figure was determined at two temperatures. In only one case did an elevated temperature result in a higher figure, and this was a case in which the catalytic activity was somewhat high. 
therefore tried with the milk under examination $(a)$ alone, $(b)$ with a fresh addition of peroxide, $(c)$ with the addition of fresh milk; $(b)$ and $(c)$ being applied only when a negative reaction was obtained with $(a)$.

C. H. La Wall (ANaLYst, 1909, 34, 160) found that the reaction with benzidine disappeared at an earlier stage, after addition of peroxide, than that with paraphenylenediamine, and concluded that different enzymes were involved in the two cases. The present experiments do not confirm this.

These three reagents are not equally applicable in all circumstances. The benzidine reaction is extremely brilliant and sensitive, but is much affected by the conditions under which the test is performed. Strong positive reactions are obtained only when the peroxide is carefully added and not intimately mixed with the milk, the best condition being that in which the peroxide is floated on to the surface of the milk and allowed to diffuse. In the case of a milk which already contains peroxide this condition is unattainable, and the brilliancy and certainty of the reaction are much diminished. The ortol reaction is adversely affected by the presence of excess of peroxide, and is, perhaps, rather less sensitive to a very small amount of peroxidase; the paraphenylenediamine reaction is not affected by a considerable excess of peroxide, and is, on the whole, probably the most generally applicable of the three. Numerous trials, in addition to those detailed above, were made with different concentrations of peroxide, and no evidence was obtained that the reactions are due to different enzymes, due allowance being made for the susceptibility of the reagents, especially benzidine, to the conditions existing. It may be here observed that with colour reactions of this nature, in which time is also a factor, distinct positives and distinct negatives form sharp contrasts, but as the peroxide or peroxidase disappears, there comes a time when it is doubtful whether the reaction should be classed as positive or negative.

That a negative reaction may be due to the absence of peroxide or of peroxidase or of both may be seen from the tables. For instance, in the case of Milk IV., in the portion kept at $27^{\circ} \mathrm{C}$., the reactions with the milk alone at from four to eleven days were all negative or nearly so, although approximately 0.07 per cent. of peroxide was present ; with fresh milk added the reactions were all positive ; the peroxidase had thus been destroyed, while the peroxide persisted. In the portion kept at $15^{\circ} \mathrm{C}$., at four days there was little peroxide left, but sufficient peroxide and peroxidase to give the reactions; at later periods the reactions were all negative, with the exception of a few doubtful ones, with milk alone, with fresh peroxide added, and with fresh milk added, showing that the peroxide and the peroxidase had both disappeared.

In the case of Milk III., at the end of four days the portion kept at $15^{\circ} \mathrm{C}$. the peroxide had disappeared, and consequently negative reactions were obtained with the milk alone and with fresh milk added; positive reactions were given with fresh peroxide, however, showing that the peroxidase had not disappeared. In the portion kept at $27^{\circ} \mathrm{C}$. the exact reverse had occurred, the peroxide being still present and the peroxidase having disappeared.

In Milk V., which had received a small original addition of peroxide, after one day the portion kept at $14^{\circ} \mathrm{C}$. contained peroxidase but no peroxide; that kept at $27^{\circ} \mathrm{C}$. contained neither. 
Owing to this destruction of peroxidase by peroxide it is thus necessary, when testing for the presence of the latter, to add some fresh milk as well as the reagent used, in order to insure the presence of peroxidase. Also, although peroxide may not be actually present, it may at times be inferred that it had at one time been present, provided that the milk had not been previously heated. This possibility of the milk having been previously heated must always be considered in relation to these tests for peroxide, though the addition of fresh milk will be effective in such a case. Conversely, the possibility of the milk having received an addition of peroxide must be considered when these reactions are used for the detection of previous heating, since a "peroxidised" and a heated mill will, in certain circumstances; react in exactly the same manner.

\section{Discussion.}

The President remarked that under even the best conditions the study of enzyme action was beset by many difficulties, and Mr. Hinks was to be congratulated on having, in face of such complications as were met with in the case of milk, approached so nearly to a definite conclusion.

Mr. C. Revis said that the fact of the persistence of hydrogen peroxide was well known to those concerned with the practical handling of milk. It was, indeed, one of the almost insurmountable difficulties connected with certain processes for sterilising milk with hydrogen peroxide. When such processes first came into use, it was considered that it would be quite easy to add sufficient hydrogen peroxide to destroy all the organisms, and that the hydrogen peroxide would not persist, but would itself be destroyed by the organisms or by the organic matter, leaving a sterile liquid, in which there would be no injurious substance left. It was found, however, that if hydrogen peroxide was added in sufficient quantity to bring about sterilisation, a pronounced taste was produced in the milk, and the addition of some catalase, which would destroy the hydrogen peroxide after sterilisation had taken place, was found to be necessary. He was pleased to find that Mr. Hinks had used Koning's method of measuring catalytic activity. It was an excellent method, but, judging from the literature, apart from the original author, Mr. Hinks and he were the only two workers who had used it. The gasometric method was exceedingly difficult to obtain good results with. Dr. Harden and Miss Lane-Claypon had used it in their experiments in the best possible manner. In Koning's process there certainly was some occlusion of iodine by the casein, but if the experiments were carried out in a comparative manner, with the necessary precautions, the results were excellent. It was important, in an investigation of this kind, that the milk used should be, as in some of Mr. Hinks's experiments, obtained direct from the cow, because the catalase, or peroxydase, or whatever it was that destroyed the peroxide, did not arise from one source alone. According to some authorities, these destructors of peroxide were present in milk in the udder, this conclusion being based on the fact that freshly drawn milk was in many cases capable of destroying hydrogen peroxide. This, however, did not necessarily mean that the milk in itself contained catalase. Grimmer had made glycerol extracts of mammary tissue, and 
had found these to have a strong catalytic activity. There was no doubt that the cellular elements which were present in milk always had a strong catalytic activity, and he had recently obtained evidence that these cellular elements might be actually dissolved in the milk itself whilst in the udder. Unfortunately, however, the bacteria occurring in milk also produced a good deal of catalase, and it was these multiple sources of catalase which complicated all experiments. If both natural catalase and bacteria were present, the result all depended upon the quantity of peroxide added and the temperature employed. If so much peroxide were added that all bacteria were destroyed, then natural catalase alone came into action, and if it were destroyed before the peroxide was completely used up, then peroxide remained. If bacteria were not destroyed, the excess peroxide was gradually destroyed as bacterial catalase developed. The course of the action was also greatly modified by the type of bacterial development which took place.

In Mr. Hinks's three cases the partial destruction of peroxide occurring in experiment " $A$ " would be due to the catalase of the milk, and so also in experiment " $B$," since in the interval of twenty-four hours there would be but a slight multiplication of bacteria, but in experiment " $\mathrm{C}$ " the bacteria would have multiplied enormously, producing sufficient catalase to complete the destruction of the peroxide immediately.

Mr. W. Partridge remarked that neither Mr. Hinks nor Mr. Revis had mentioned whether, as a matter of fact, hydrogen peroxide was used at all for preservative purposes. Its use under certain restrictions was provided for in the Milk and Cream Regulations, but he had never found it in milk or cream or seen any cream labelled as containing it. Mr. Hinks's experiments might perhaps be the means of removing an injustice hitherto suffered by certain oxidising disinfectants, the action of which was supposed to be due to organic peroxides. From the fact that such disinfectants were found to have as strong an action after being left in contact with organic matter as before, it used to be assumed that there was no peroxide present ; but Mr. Hinks's experiments clearly showed that peroxide could exist and remain in presence of organic matter.

Mr. REvis said that hydrogen peroxide was never used for preserving milk.

The President thought it probable that the increase in catalytic activity which occurred after a few days' rest was due to bacterial growth. With regard to the question of the presence of catalase in milk as drawn from the udder, he did not see any reason why it should not occur in solution, apart from any cellular elements, as in preserved yeast prepared by Buchner's method, where there was not any question of cellular elements. In the experiments with Milk V. and Milk VI., of which the catalytic activity was 132 and 39 respectively, he should have expected a considerable difference in the quantity of hydrogen peroxide destroyed during the first ten minutes. It was, however, approximately the same in both cases, which seemed curious.

Mr. Hinks said that generally speaking one would expect the destruction of peroxide to correspond to the catalytic activity, but there were many disturbing influences, though as a rule these followed very much the same course. Milk V. was certainly not very fresh. Mr. Revis had mentioned that hydrogen peroxide was never used in milk, but attempts had been made to use it. There was a great differ- 
ence as regards persistence between $0 \cdot 1$ and $0 \cdot 2$ per cent. No unqualified statement could be made as to how long it would last, but he should think that probably, even with perfectly fresh milk, 0.1 per cent. would not last twenty-four hours, while 0.2 per cent. would probably last for a long time. Koning's method, of course, did not measure the actual quantity of catalase present or the actual catalytic activity, but merely yielded an empirical figure. This would vary if the temperature or the time were altered, but when obtained under the same conditions it was very useful for comparing different samples of milk. As to whether catalase did or did not exist in milk drawn under sterile conditions he was not prepared to speak positively; but when a sample taken immediately after milking showed a figure of 32 , and when this only rose to 34 after forty-eight hours, and then rose rapidly, it would seem reasonable to suppose that the catalase was there to start with.

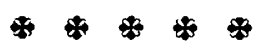

